\title{
O Ensino de Avaliação Funcional Descritiva para Professores na Alfabetização em Língua Portuguesa nas Séries Iniciais ${ }^{1}$
}

\author{
Jair Lopes Junior \\ Ana Paula Araújo Fonseca \\ Mariana Francisco Giuzio \\ Universidade Estadual Paulista
}

\begin{abstract}
RESUMO
Este estudo objetivou ensinar repertórios que definem a execução de avaliações funcionais descritivas a um professor (P1) que ministrava conteúdos de Língua Portuguesa nas séries iniciais. Na Etapa 1 foram registradas aulas de duas unidades didáticas consecutivas. Em seguida, P1 respondeu a um roteiro sobre as aulas da primeira unidade. As respostas ocorreram na ausência e, em seguida, diante do vídeo das respectivas aulas. Na Etapa 2 ocorreu a apresentação de um modelo de avaliação funcional descritiva elaborado pelos pesquisadores sobre episódios selecionados do vídeo exibido. Após exposição ao vídeo das aulas da segunda unidade, P1 elaborou um modelo e, ao final, ocorreu a exposição ao modelo dos pesquisadores. Na Etapa 3 foram gravadas as aulas da terceira unidade e, na sequência, $\mathrm{P} 1$ respondeu às mesmas indagações da etapa inicial. Práticas oralistas prescindindo da identificação de relações de controle de estímulo foram registradas independente do contato com os vídeos e com os modelos de avaliação funcional. Na Etapa 3, o desempenho em sala de aula sugeriu controle por dimensões dos modelos apresentados pelos pesquisadores. Restrições na aprendizagem de repertórios que definem a execução de avaliações funcionais descritivas foram vinculadas com propriedades dos procedimentos adotados.
\end{abstract}

Palavras-chave: avaliação funcional descritiva; análise do comportamento; formação de professores; ensino de Língua Portuguesa.

\section{ABSTRACT \\ Teaching Descriptive Functional Assessment to Portuguese Language Literacy Teachers in Primary Schools}

This study verified if teacher's (P1) exposure to a video of their own Portuguese language lesson and to researchers' functional descriptive assessment models would aid in the learning of behavioral repertoires that define this kind of functional assessment. In Phase 1, Portuguese language classes taught by P1 on two didactic units (DU 1 and DU 2) were recorded and P1 was exposed to interview about DU 1 classes in the absence and in the presence of the DU 1 video. In Phase 2, P1 is exposed to the researchers' functional descriptive model about DU 1 classes. Following that, the DU 2 videos were showed and P1 was asked to make a functional descriptive assessment model about the DU 2 video. After, P1 came into contact with researchers' functional descriptive model of DU 2 classes. Finally, in Phase 3, DU 3 Portuguese language classes were recorded and P1 was exposed to the same Phase 1 questions. In the absence of DU1 and DU 2 video recorded classes, P1 early teaching repertoires stressed oral without knowledge about possible stimulus control relations in P1 classes. P1 teaching strategies in Phase 3 were related to past researchers' functional interpretative models. Learning limitations about behavioral repertories used to make functional descriptive assessment were related with characteristics of the procedures adopted.

Keywords: descriptive functional assessment; behavior analysis; teacher education; teaching of Portuguese language.

Investigações sobre procedimentos e processos de desenvolvimento profissional de professores que atuam nas séries iniciais do ensino fundamental evidenciam distintas orientações epistemológicas e metodológicas (Alves, 2007; Evangelista \& Shiroma, 2007; Nunes, 2008). No âmbito do presente trabalho, advoga-se que 
propostas de investigação sobre o desenvolvimento profissional de professores, fundamentadas na Análise do Comportamento, devem considerar como objeto de estudo prioritário, dentre outros aspectos, as diferentes classes de resposta que definem o ensinar. A prioridade, portanto, aponta para o ensino de recursos metodológicos que viabilizem o desenvolvimento de estratégias de ensino diretamente vinculadas com a rotina e os conteúdos que definem a atuação profissional do professor. Nesta investigação, em termos de conteúdos, temas inseridos na área curricular de Língua Portuguesa foram selecionados. Quanto aos recursos metodológicos, a escolha recaiu sobre a avaliação funcional descritiva.

A área curricular de Língua Portuguesa sustenta relevância inconteste para a alfabetização nas séries iniciais do ensino fundamental. A reincidência de desempenhos insatisfatórios nesta área curricular em programas nacionais de avaliação do ensino fundamental (Scarvoldelli, 2006) parece indicar, ao menos no que se refere à dimensão estritamente pedagógica, que as diretrizes e as orientações expressas nos Parâmetros Curriculares Nacionais de Língua Portuguesa (Brasil, 1997), ainda que necessárias, mostram-se insuficientes para assegurar, aos docentes, aprendizagens profissionais de planejamento e de execução de condições de ensino consistentes com os objetivos e metas que definiram as reformas educacionais oficializadas após a promulgação da Lei de Diretrizes e Bases da Educação Nacional (Lei 9.396, de 20/12/1996). Esta insuficiência justifica a continuidade das investigações comprometidas com o fornecimento de contribuições para o aprimoramento de práticas educativas devidamente fundamentadas cientificamente.

Sobre o recurso metodológico escolhido, cumpre salientar que, nas últimas décadas, a literatura em Análise do Comportamento tem concentrado interesse na investigação de estratégias que poderiam contribuir para a aquisição e o desenvolvimento de repertórios que definem a execução de análises ou de avaliações de possíveis propriedades funcionais de determinados comportamentos alvos (functional assessment; Iwata $\&$ cols., 2000). Admite-se que a identificação e a caracterização de propriedades funcionais resultam da utilização de estratégias indiretas (entrevistas, questionários) e diretas (análises descritivas narrativas baseadas na observação direta de eventos sequenciais), bem como na manipulação de condições ambientais antecedentes e consequentes à ocorrência de determinadas respostas (Daly, Witt, Martens \& Dool, 1997; Horner, 1994; Iwata \& cols., 2000; Mace, 1994; Mace \& Lalli,
1991; Moore e cols., 2002; Neef \& Iwata, 1994; Noell e cols., 2000; Ulian, 2007; Wallace e cols., 2004).

O ensino de repertórios que viabilizariam a implementação de procedimentos de análise e de avaliação funcional constituiu-se, portanto, em objeto de investigações que envolvem diferentes técnicas e aprendizes com diversificadas formações, acadêmica e profissional, em contextos de pesquisa e de atuação distintos. Dentre as diferentes modalidades de avaliação funcional indicadas pela literatura (Sturmey, 1996; Ulian, 2007), duas assumem particular relevância para o estudo ora relatado: análise funcional ${ }^{1}$ experimental e a avaliação funcional descritiva.

Em termos genéricos, nos procedimentos de análise funcional experimental há programação da exposição de clientes, estudantes, ou mesmo de atores, a sucessivas contingências com propriedades distintas, a saber, reforçamento positivo, reforçamento negativo, ausência de estimulação ambiental programada contingente (ou não) à ocorrência de repertórios alvos (por exemplo, comportamentos agressivos, autolesivos, de oposição, dentre outros). Diante destas exposições, dois conjuntos de repertórios são considerados como medidas da aprendizagem deste recurso de avaliação: a) a interpretação, por inspeção visual, dos padrões do responder dentro e entre as contingências que fundamente a proposição de hipóteses sobre a determinação destes padrões (Hagopian e cols., 1997); b) a atuação dos aprendizes em tais exposições, a saber, pela liberação de sequências prescritas de eventos antecedentes e consequentes à ocorrência de determinadas respostas.

Iwata e cols. (2000) demonstraram, com estudantes de Psicologia, resultados positivos na aprendizagem de repertórios consistentes com a execução de análises funcionais experimentais em situações simuladas, nas quais outros estudantes foram treinados a exercer a função de clientes. Posteriormente, Moore e Fisher (2007) relataram resultados positivos, desta feita, com bacharéis em Psicologia, tanto em situações simuladas, quanto em sessões de atendimento clínico com clientes inscritos em serviços de atendimento psicológico.

Os resultados positivos em tais programas de treinamento não se mostram restritos a populações vinculadas acadêmica e profissionalmente à Psicologia. Professores do ensino elementar regular, tanto quanto de educação especial, de modo individual (Moore e cols., 2002) ou coletivamente, sob a forma de workshops (Wallace e cols., 2004), implementaram, em situações simuladas, bem como em sala de aula, 
procedimentos consistentes com a execução de análises funcionais experimentais envolvendo contingências de reforçamento positivo e negativo adotadas por Iwata e cols. (2000).

Em seu conjunto, os estudos anteriormente mencionados documentaram experiências bem sucedidas de ensino de uma modalidade de avaliação funcional análise funcional experimental - considerando, como medida de aprendizagem, o desempenho dos participantes em atividades de leitura e de exame escrito sobre conceitos e exemplos deste recurso metodológico, bem como as atuações em algumas contingências simuladas e naturais que envolvem, segundo os próprios autores, restritas topografias de respostas, visto que representam apenas um subconjunto dos repertórios necessários para a implementação adequada de uma análise funcional.

A prioridade concedida à modalidade de análise funcional experimental, com utilização de um número reduzido de contingências envolvendo respostas topograficamente simples (p.ex., solicitações orais para interrupção imediata de comportamentos autolesivos e agressivos, "tapinha" nas costas contingentes à emissão de respostas esperadas e solicitadas, apresentação de atividades (demandas/exercícios) com instruções orais, dicas verbais e não verbais, elogios e remoção de materiais relacionados com a execução das atividades propostas) parece ter se constituído em condição relevante para a consolidação de uma área de pesquisa comprometida com a inserção deste recurso metodológico em diferentes contextos da atuação profissional (Carr, 1994).

Em contraste com o êxito assinalado nos programas de treinamentos de repertórios relacionados com a execução de análises funcionais experimentais, a literatura registra dificuldades na implementação, em ambientes naturais, de uma outra modalidade de recursos metodológicos de avaliação funcional, a saber, a avaliação funcional descritiva (Fox \& Davis, 2005; Scott e cols., 2005; Van Acker e cols., 2005). Admitese que a avaliação funcional descritiva define-se pela observação direta de interações comportamentoambiente sob condições ambientais nas quais naturalmente elas ocorrem, prescindindo, todavia, da manipulação de variáveis funcionalmente relacionadas com propriedades de determinados repertórios. Enquanto recurso metodológico, a avaliação funcional descritiva objetiva, mediante a obtenção de dados sobre eventos antecedentes e subsequentes aos repertórios selecionados, fornecer evidências que possam subsidiar hipóteses sobre possíveis funções operantes destes repertórios. Assim, dados derivados da execução de avaliações funcionais não autorizam ou permitem conclusões definitivas sobre relações funcionais (Bijou, Peterson \& Ault, 1968; Borrero \& Borrero, 2008; Lerman \& Iwata, 1993; Mace e cols., 1991; Sturmey, 1996).

Lerman e Iwata (1993) descreveram três tipos de avaliações funcionais descritivas. Os três tipos são discrimináveis quanto aos repertórios que definem a execução de uma avaliação funcional descritiva e, consequentemente, nas dimensões de análise priorizadas por tais repertórios. O Tipo 1 prioriza a descrição da distribuição temporal do comportamento. Neste tipo há o predomínio da utilização de técnicas que registram a ocorrência dos repertórios selecionados dentro de blocos (intervalos) de tempo com o objetivo de identificar distribuições consistentes na ocorrência de tais repertórios. Muito embora este tipo produza dados quantificáveis, ele não prevê a identificação de eventos antecedentes e consequentes específicos, sendo que ocorrerá apenas a detecção daquelas condições ambientais relacionadas com o comportamento em termos de bases temporais regulares. O Tipo 2 prioriza um tratamento narrativo na observação e no registro das interações comportamento-ambiente com informações expressas em termos do relato de antecedentes, resposta e consequência, ou seja, predominam descrições de eventos que ocorrem imediatamente antes e após a emissão de exemplos dos repertórios selecionados. Tais registros narrativos objetivam determinar a consistência com a qual eventos antecedentes e subsequentes específicos mostram-se contíguos aos repertórios selecionados. Estes registros dificilmente são quantificados e usualmente fazem referência a determinados eventos apenas diante da ocorrência do repertório selecionado, ou seja, ignora-se a possibilidade de que a manifestação de tais eventos esteja correlacionada com a não ocorrência de tal repertório. O terceiro tipo de avaliação funcional descritiva produz dados passíveis de quantificação mais refinada, bem como permite o registro de eventos que ocorreram independente do repertório selecionado. As técnicas utilizadas priorizam o registro da ocorrência de eventos especificados previamente e de comportamentos exibidos pelo sujeito e por aqueles que interagem com ele em sessões de 15 a 45 minutos aproximadamente. Este tipo de análise objetiva identificar sequências de comportamentos e de seus correlatos ambientais ao longo do tempo.

Uma vez caracterizados os diferentes tipos de avaliação funcional descritiva, com as suas respectivas técnicas e repertórios necessários, coloca-se uma questão adicional acerca das condições que possivelmente contribuíram para estender o alcance de tais 
recursos metodológicos para contextos aplicados, a saber, para situações nas quais os mesmos foram utilizados na análise de contingências naturais, em complemento aos estudos nos quais as características das contingências eram experimentalmente pré-definidas.

Dentre os diferentes contextos, o presente trabalho priorizou instituições escolares. Repp (1994) argumentou que três conjuntos de publicações foram de fundamental importância para fortalecer a utilização de recursos analíticos funcionais em ambiente escolar. $\mathrm{O}$ primeiro conjunto concentra-se em duas características do trabalho de Carr (1977): a) nas hipóteses sobre possíveis variáveis controladoras de repertórios autolesivos, mais especificamente, as hipóteses do reforçamento positivo, do reforçamento negativo e da autoestimulação; e, principalmente, b) na necessidade de que a escolha e a utilização de procedimentos de intervenção estivessem devidamente amparadas na identificação de propriedades ou de relações funcionais (respostas para indagações sobre porque repertórios autolesivos existem). O segundo conjunto envolveu as publicações que priorizaram a identificação de variáveis funcionalmente relacionadas com repertórios autolesivos mediante utilização de situações análogas experimentalmente àquelas nas quais os repertórios ocorriam. Por seu turno, o terceiro conjunto, de modo mais específico, consistiu nas demonstrações, também mediante utilização de situações experimentalmente análogas, das relações entre variáveis instrucionais e a ocorrência de comportamentos inadequados (school based behavior problems; Repp, 1994). Como exemplos de tais variáveis, caberia mencionar a escolha das tarefas, variações nas tarefas apresentadas, regularidade das instruções, vincular (embutir) exigências de baixa probabilidade de execução em séries com tarefas com elevada probabilidade e redução planejada nas dificuldades das tarefas.

Segundo Repp (1994), a utilização de situações experimentalmente análogas (analogue classroom setting; Meyer, 1999) nas quais a avaliação funcional dependia da produção de condições muito possivelmente relacionadas, de modo direto, com a ocorrência dos repertórios inadequados, não se mostrou isenta de controvérsias no contexto escolar. Para superar tais controvérsias foi necessária a proposição de procedimentos que garantissem avaliações padronizadas e replicáveis das hipóteses fundamentadas em interpretações ambientalistas dos comportamentos inadequados observados em contexto escolar. Os procedimentos que cumpriram, de modo satisfatório, tais exigências, compreendiam três fases (Repp, 1994; Sprague
\& Horner, 1992): a) Fase 1: nesta fase há combinação de dados de entrevistas e de observação direta, sem manipulação de eventos, com o intuito de formulação de hipóteses sobre propriedades funcionais dos repertórios selecionados; b) Fase 2: definida pela ocorrência da coleta formal dos dados de linha de base com construção das tabelas de contingências para efeito de confirmação, ou não, das hipóteses formuladas na fase anterior; c) Fase 3: por fim, tem-se a verificação da validade das hipóteses formuladas nas fases anteriores, ou seja, ocorrem intervenções para testar tais hipóteses. Vale destacar que as fases descritas, em particular as Fases 1 e 2, não impõem restrições quanto ao tipo de avaliação funcional descritiva a ser efetuada, segundo a classificação proposta por Lerman e Iwata (1993).

Um aspecto relevante da literatura acima considerada reside em apontar, quando a ênfase recai na modalidade descritiva de avaliação funcional, que existem análises sobre condições antecedentes favoráveis à sua implantação, bem como classificações quanto a subtipos desta modalidade e caracterizações de procedimentos nos quais a mesma estaria inserida. Contudo, este acervo parece concentrar o foco na utilização deste recurso metodológico prioritariamente por pesquisadores que elegeram como objeto de estudo comportamentos inadequados manifestos em ambiente escolar. Em franco contraste com os resultados da implantação de recursos de análise funcional experimental por graduandos e profissionais de diferentes áreas de formação (Iwata e cols., 2000; Moore e cols., 2002; Wallace e cols., 2004), registra-se uma nítida carência de estudos nos quais o ensino e a implementação de avaliações funcionais descritivas tenham se constituído em objeto de investigação.

De modo coerente com a lacuna ou ausência de produção científica sobre o ensino de recursos funcionais descritivos, praticamente uma década após as análises de Repp (1994) sobre procedimentos de avaliação funcional adotados por pesquisadores no estudo de school based behavior problems, a literatura acusa convergência em estimar como insatisfatórios os resultados registrados na avaliação de práticas adotadas por membros de escolas na condução de avaliações funcionais comportamentais, bem como na implementação de planos de intervenção comportamentais. As deficiências concentram-se, principalmente, na definição e na mensuração dos repertórios de investigação selecionados, na utilização de técnicas de registro muito distintas das práticas adotadas na rotina escolar, na verificação de hipóteses que deveria preceder a intervenção e no estabelecimento de vínculos 
entre os dados da avaliação e os programas de intervenção (Scott e cols., 2005; van Acker e cols., 2005).

Temos, portanto, que o problema ou indagação de pesquisa que justifica a investigação ora relatada encontra-se, assim, demarcado: quais condições se mostrariam efetivas para o ensino de repertórios que definem a execução de avaliações funcionais descritivas com ênfase no tratamento narrativo da observação e do registro das interações comportamento-ambiente (Tipo 2; Lerman \& Iwata, 1993), para professores da rede pública estadual na escola?

Este estudo objetivou documentar contribuições da Análise do Comportamento para programas de pesquisa aplicada com foco na formação continuada (em serviço) e no desenvolvimento profissional de docentes (Rodrigues, 2005; Zanotto, 2000). De modo mais específico, procurou-se ampliar o alcance de programas de pesquisa comprometidos com o ensino de recursos metodológicos de avaliação funcional descritiva em contexto aplicado. Assim, diferentemente das tradições de pesquisa que concentram ênfase nos school based problems (Repp, 1994), este estudo priorizou o ensino de recursos de avaliação funcional descritiva para professores que ministram conteúdos curriculares de Língua Portuguesa nas séries iniciais do Ensino Fundamental.

\section{MÉTODO}

\section{Participantes}

O estudo contou com a participação de um professor (P1) lotado em uma escola da rede pública estadual, localizada em região periférica da cidade e que atende crianças de nível sócio econômico baixo. P1 ministrava aulas para o $5^{\mathrm{a}}$. ano $/ 4^{\mathrm{a}}$. série do ensino fundamental. Em termos de formação acadêmica, P1 cursou Magistério e Licenciatura em Pedagogia e não apresentava qualquer experiência prévia de participação em estudos da área de Psicologia. P1 possuía seis anos de exercício profissional da docência. A participação de P1 ocorreu por indicação da coordenação pedagógica da escola e foi oficializada com a assinatura do Termo de Consentimento Livre e Esclarecido, conforme aprovado pelo Comitê de Ética em Pesquisa da unidade universitária a qual os pesquisadores estavam filiados.

\section{Material}

Foram utilizados para coleta, registro, tabulação e análise dos dados, os seguintes materiais: uma filmadora portátil, gravador digital de áudio, fotocópias dos roteiros de entrevista, um televisor, um aparelho reprodutor (leitor) dos registros em vídeo da filmadora.

\section{Procedimento}

Todas as sessões de coleta de dados foram realizadas na escola em horários estabelecidos com o consentimento da coordenação pedagógica. $\mathrm{O}$ procedimento adotado consistiu de três etapas.

Etapa 1. O objetivo geral desta etapa foi o de verificar as principais características da interação entre as práticas de ensino e de avaliação adotadas por $\mathrm{P} 1$ e os desempenhos emitidos pelos alunos, considerando as seguintes medidas comportamentais: o relato verbal do professor e dados de observação das aulas por ele ministradas. A Etapa 1 foi subdividida em três fases.

Etapa 1/Fase 1. Consistiu no registro, em vídeo, das aulas referentes a duas Unidades Didáticas (UD) ministradas consecutivamente. P1 definiu os temas e conteúdos, bem como o respectivo número de aulas para cada unidade, de acordo com o seu planejamento pedagógico. A única exigência foi a de que os temas e, portanto, as respectivas aulas, fossem consecutivas, isto é, sem interrupção entre o final das aulas da primeira unidade e o início das aulas da unidade subsequente. Precedendo ao início das filmagens, um período de ambientação do pesquisador responsável pelas gravações com os alunos da classe foi efetuado. Neste período, o pesquisador permaneceu na sala em aulas de diferentes áreas curriculares (não somente de Língua Portuguesa), estabelecidas pelo professor, ora sem a filmadora, ora com a filmadora desligada e, por fim, com a mesma ligada. A ambientação foi finalizada mediante a avaliação conjunta, do professor e do pesquisador, de que os comportamentos dos alunos não se mostravam alterados diante da presença deste último. Após a ambientação, foi iniciado o período de gravação em vídeo das aulas referentes a cada UD. Cada UD foi definida pelo início, meio e final do tratamento de um mesmo tema pelo professor. Durante as filmagens, o pesquisador posicionou-se em locais, dentro da sala, devidamente autorizados pelo professor, sem interações que pudessem comprometer a execução das atividades do professor e dos alunos. Em todas as gravações, os registros em vídeo priorizaram as ações emitidas por P1 sobre os temas selecionados diante dos alunos coletivamente e diante de grupos menores de alunos, bem como as ações dos alunos diante das quais tais respostas de P1 ocorreram, além das ações dos alunos posteriores a tais respostas. A instalação e a retirada dos equipamentos utili- 
zados ocorreram, com o devido planejamento, antes e após o término das aulas indicadas pelo professor.

Etapa 1/Fase 2. Após a finalização dos registros em vídeo das aulas da UD2, o professor foi exposto ao Roteiro de Entrevista 1. Todas as questões deste roteiro faziam referência às aulas da UD1. O Roteiro de Entrevista 1 indagou sobre: a) as estratégias utilizadas no ensino do tema da UD1; b) os objetivos das estratégias mencionadas; c) os efeitos obtidos com a utilização das estratégias; d) as medidas comportamentais correspondentes a tais efeitos; e) possíveis influências dos efeitos mencionados nas ações do professor para ensinar o tema da UD1.

Etapa 1/Fase 3. Na Fase 3, de início, os pesquisadores deveriam selecionar, diante do vídeo das aulas gravadas na UD1, trechos (episódios) de cenas de interações professor-aluno que indicassem as condições dispostas diante das quais determinadas características das respostas dos alunos foram emitidas, ou seja, como critério de seleção deveriam ser escolhidos episódios que sugerissem possíveis relações de funcionalidade entre propriedades das ações observadas do professor e de seus alunos. Não havia restrições quanto ao número de episódios selecionados, tampouco quanto à duração dos mesmos.

Após a seleção dos episódios, P1 foi exposto ao vídeo, na íntegra, das aulas da UD1. Os pesquisadores informaram que, após a apresentação dos registros das aulas em vídeo da UD1, ocorreria uma entrevista com utilização do mesmo roteiro previamente apresentado (Roteiro de Entrevista 1), sendo que a função do vídeo seria a de favorecer a lembrança das aulas ministradas em razão do intervalo de tempo já transcorrido. Informaram também que, durante a exibição do vídeo, seria indicado oralmente o início e o final de trechos que foram selecionados para melhor direcionar as discussões posteriores sobre o roteiro de entrevista mencionado.

Etapa 2. O objetivo da Etapa 2 consistiu em ensinar a P1 repertórios verbais consistentes com avaliações funcionais descritivas prioritariamente sobre episódios selecionados pelos pesquisadores a partir de condições de interação planejadas entre estes e P1. À exemplo da etapa anterior, o procedimento foi subdividido em três fases.

Etapa 2/Fase 1. A primeira fase da Etapa 2 foi iniciada com a execução de uma nova entrevista. Desta feita, P1 foi exposto ao Roteiro de Entrevista 2 composto por quatro questões. Com o intuito de estabelecer condições favorecedoras para a identificação, por P1, de possíveis relações funcionais entre as suas práticas de ensino e de avaliação e os desempenhos dos alunos, o Roteiro de Entrevista 2 replicou, em relação ao roteiro anterior, questões sobre os objetivos (questão 1) e as estratégias utilizadas (questão 2) nas aulas da UD1, bem como apresentou questões que solicitaram o relato sobre as medidas comportamentais, exibidas pelos alunos e relacionadas com os objetivos pretendidos, antes (questão 3) e após (questão 4) o contato com as estratégias mencionadas (questão 2).

Etapa 2/Fase 2. Os pesquisadores informaram P1 de que, a exemplo do ocorrido na etapa anterior, seria novamente exibido o vídeo das aulas da UD1 com indicação do início e do final dos mesmos episódios que os pesquisadores haviam selecionado. Desta feita, porém, ao final do vídeo, os pesquisadores apresentariam modelos de interpretação das cenas exibidas nos episódios. Assim, ao final da exibição do vídeo, os pesquisadores apresentaram oralmente avaliações funcionais descritivas narrativas sobre os episódios selecionados das aulas da UD1.

Etapa 2/Fase 3. De início, os pesquisadores selecionaram, diante do vídeo, episódios das aulas da UD2 seguindo os mesmos critérios adotados por ocasião da seleção dos episódios das aulas da UD1 na Etapa 1/Fase 3. Na sequência, P1 foi exposto ao vídeo, na íntegra, das aulas da UD2. Precedendo a esta exposição, a seguinte instrução foi apresentada oralmente a P1:

Professor, gostaria que você assistisse ao vídeo relativo às aulas do segundo tema (UD2) que filmei na sua sala. Gostaria que você procurasse atentar para o que ocorreu de mais importante, levando em consideração: a) a obtenção dos objetivos que você estimou como os mais importantes para as aulas do segundo tema; b) a sua interação com os alunos; c) as condições que você teve para executar o tema; d) os desempenhos dos alunos diante das estratégias de ensino e de avaliação utilizadas . Fique à vontade para fazer as anotações, apontamentos, etc, que você estimar necessários. Discutiremos sobre as suas observações ao final do vídeo. Para fazer a atividade solicitada, você pode escolher quantos trechos desejar do vídeo, sem se preocupar com o tamanho de cada trecho. Caso prefira, pode solicitar que façamos uma interrupção momentânea do vídeo para as suas anotações. Em todo caso, já fizemos a seleção de alguns trechos para as nossas discussões ao final. Durante a exibição do vídeo das aulas, indicarei o início e o final dos trechos que selecionamos. Bom trabalho.

Finalizada a exposição do vídeo das aulas da UD2, os pesquisadores solicitaram comentários orais de $\mathrm{P} 1$, com base nos quatro itens mencionados nas instruções orais (acima), sobre os trechos por ele indicados, bem 
como sobre os episódios sinalizados pelos pesquisadores. Imediatamente após os comentários de P1, os pesquisadores apresentaram modelos de avaliação funcional descritiva narrativa sobre os episódios que eles haviam previamente selecionado.

Etapa 3. O objetivo da Etapa 3 consistiu em avaliar se, em novas aulas ministradas e no relato verbal sobre as mesmas, características do desempenho de P1 mostrar-se-iam relacionadas com as interações entre ele e o pesquisador dispostas nos procedimentos adotados nas etapas anteriores. A Etapa 3 foi subdividida em duas fases:

Etapa 3/Fase 1. Inicialmente foram efetuados os registros em vídeo das aulas referentes ao tema selecionado pelo professor para a UD3. Os procedimentos de filmagem foram os mesmos adotados na Etapa 1, excetuando a realização do período de ambientação.

Etapa 3/Fase 2. Com o encerramento das gravações das aulas, os pesquisadores efetuaram a seleção de episódios das aulas da UD3 para discussões posteriores com P1. Foram mantidos os mesmos critérios adotados para a seleção dos episódios das aulas da UD1 e da UD2. Além de tais critérios, foram selecionados trechos que, igualmente: a) ilustrassem a reincidência de práticas de ensino e de avaliação já registrados em episódios selecionados nas Etapas 1 (UD1) e 2 (UD2); b) indicassem possíveis alterações destas práticas no repertório de $\mathrm{P} 1$.

Após a seleção dos episódios, o vídeo, na íntegra, das aulas ministradas na UD3 foi apresentado ao professor. Antecedendo à exibição do vídeo, os pesquisadores informavam ao professor que a tarefa era a mesma executada anteriormente com o vídeo das aulas da UD2, reiterando, oralmente, as instruções acima transcritas com as devidas adaptações para a UD3. Ao final da exibição do vídeo, os pesquisadores apresentaram o Roteiro da Entrevista 3 para orientar as dis- cussões sobre os episódios selecionados e exibidos juntamente com o vídeo das aulas da UD3. O Roteiro de Entrevista 3 consistiu na junção das questões previamente apresentadas nos dois roteiros anteriores, com a inclusão de uma pergunta inicial que solicitava uma análise sobre os aspectos mais importantes observados por P1 nas aulas da UD3. Assim, o Roteiro de Entrevista 3 indagou sobre: a) os objetivos para o tema da UD3; b) os desempenhos previstos como correspondentes com os objetivos pretendidos; c) quão distante os alunos estavam dos desempenhos desejados; d) as estratégias de ensino fornecidas para a obtenção dos desempenhos desejados; e) como ocorreu a avaliação da obtenção dos objetivos; f) a obtenção ou não dos objetivos; g) ações dos alunos que sugerem que os objetivos foram alcançados; h) efeitos das ações dos alunos sobre as estratégias de ensino e de avaliação utilizadas. Após as discussões sobre as questões do roteiro, o procedimento da Etapa 3 foi finalizado com a solicitação para que P1 efetuasse uma análise comparativa das interações entre ele e os alunos exibidas nos episódios selecionados das UD2 e UD3.

\section{RESULTADOS}

Etapa 1/Fase 1. P1 escolheu os temas "Vários tipos de texto" e "Texto científico", respectivamente, para as Unidades Didáticas 1 (UD1) e 2 (UD2). Para cada unidade didática, as aulas ministradas, bem como a gravação em vídeo das mesmas, ocorreram de acordo com a sequência estabelecida pelo professor, sem interrupções para apresentação de conteúdos distintos daqueles previstos para os temas selecionados.

Etapa 1/Fase 2. Imediatamente após o final dos registros das aulas referentes à UD2, P1 foi exposto ao Roteiro de Entrevista 1, sem contato com os registros em vídeo. Na Tabela 1 consta uma síntese das respostas fornecidas por P1.

TABELA 1

Síntese das Respostas de P1 na Primeira Exposição ao Roteiro de Entrevista 1 (Antes da Exibição dos Vídeos)

\begin{tabular}{l|l}
\hline Questões / Roteiro 1 & Síntese das respostas emitidas por P1 (antes do contato com vídeo). \\
\hline Estratégias de ensino utilizadas & Exposição oral e divisão da sala em grupos. \\
\hline Objetivos das estratégias mencionadas & Explanar tema; dar visão geral; que os alunos soubessem trabalhar em grupos. \\
\hline $\begin{array}{l}\text { Efeitos obtidos com a utilização das } \\
\text { estratégias }\end{array}$ & $\begin{array}{l}\text { Foi muito cansativo e alunos não prestaram atenção. Professor identificou que para alguns } \\
\text { alunos foi ainda mais difícil, pois eles têm propenão a ficar com menos atenção e disposição } \\
\text { para outras atividades. Alguns alunos tiveram mais dificuldade em realizar as tarefas, mas a } \\
\text { maioria tentou aprender a trabalhar em grupo. }\end{array}$ \\
\hline $\begin{array}{l}\text { Medidas comportamentais correspon- } \\
\text { dentes aos efeitos }\end{array}$ & $\begin{array}{l}\text { Alunos ficaram agitados. Sempre tinha que retomar assunto da aula, o que a tornou mais } \\
\text { cansativa. Alunos não ficaram sentados e não prestaram atenção. }\end{array}$ \\
\hline $\begin{array}{l}\text { Possíveis influências dos efeitos para o o } 0 \\
\text { ensino do tema }\end{array}$ & $\begin{array}{l}\text { Influenciou, pois parou mais vezes a aula para explicar, embora tenha seguido o planeja- } \\
\text { mento da aula estabelecido previamente. }\end{array}$ \\
\hline
\end{tabular}


Etapa 1/Fase 3. Foram, inicialmente, selecionados quatro trechos (episódios) derivados dos registros das aulas da UD1. A Tabela 2 informa sobre características dos episódios selecionados.

\section{TABELA 2}

Principais Características de Cada Episódio Selecionado das Aulas Ministradas por P1 na Unidade Didática 1 (UD1), Cujo Tema foi "Vários Tipos de Textos"

\begin{tabular}{l|l}
\hline Episódio & Características \\
\hline \multirow{2}{*}{1} & $\begin{array}{l}\text { P1 solicitou oralmente que grupos de três alunos se reunissem para analisar textos de uma } \\
\text { mesma categoria. Em grupos, alunos discutiram, solicitando, com frequência variada, a pre- } \\
\text { sença de P1. Quando solicitado, P1 interagiu com os grupos. Na ausência de solicitação, P1 } \\
\text { permaneceu andando pela sala, sem comentar os trabalhos dos alunos. Na sequência, cada } \\
\text { grupo apresentou para a sala os textos analisados. P1 fez perguntas aos trios enquanto eles } \\
\text { apresentavam. As respostas, quando emitidas, foram fornecidas por alunos distintos daqueles } \\
\text { designados por P1. }\end{array}$ \\
\hline 3 & $\begin{array}{l}\text { Enquanto os grupos apresentavam para a classe os textos analisados, P1 indagou sobre o tipo } \\
\text { de texto apresentado, sendo que, diante da hesitação ou da latência na produção de respostas } \\
\text { pelos alunos indagados, P1 respondia diretamente às questões por ele formuladas. }\end{array}$ \\
\hline 3 & $\begin{array}{l}\text { P1 expôs oralmente o conteúdo, mesclando as explicações com questões para os alunos. } \\
\text { Interrompia, de modo reincidente, as explicações e as indagações para fazer anotações na } \\
\text { lousa para os alunos copiarem. Diante do predomínio da cópia pelos alunos, P1 respondeu as } \\
\text { indagações sem obtenção de medidas de compreensão pelos alunos dos conteúdos expostos } \\
\text { oralmente e por escrito. }\end{array}$ \\
\hline $\begin{array}{l}\text { P1 solicitou aos alunos que classificassem os diferentes tipos de texto, na ausência de defini- } \\
\text { ções e de modelos a respeito destes diferentes tipos de textos. }\end{array}$ \\
\hline
\end{tabular}

Após a seleção dos episódios da UD1, P1 foi exposto ao vídeo, na íntegra, das aulas da UD1, com duas informações adicionais: $1^{\text {a }}$ ) de que, durante a exibição do vídeo, haveria indicação prévia, pelo pesquisador, do início e do final de trechos selecionados com base na entrevista anterior; $2^{\mathrm{a}}$ ) de que, ao final da exibição, eles conversariam novamente sobre os temas já discutidos na entrevista anterior que ocorreu sem o contato com o vídeo. A Tabela 3 apresenta uma síntese das respostas fornecidas por P1 na segunda exposição ao Roteiro da Entrevista 1.

TABELA 3

Síntese das Respostas de P1 na Segunda Exposição ao Roteiro de Entrevista 1 Diante da Exibição do Vídeo

\begin{tabular}{l|l}
\hline Questões / Roteiro 1 & Síntese das respostas emitidas por P1 (após do contato com vídeo). \\
\hline $\begin{array}{l}\text { Estratégias de ensino utiliza- } \\
\text { das }\end{array}$ & $\begin{array}{l}\text { Dividir a sala em grupo de três alunos; fazer exploração teórica do tema utilizando lousa; fornecer textos } \\
\text { para alunos observarem; pedir produção de texto sobre o assunto discutido. }\end{array}$ \\
\hline $\begin{array}{l}\text { Objetivos das estratégias } \\
\text { mencionadas }\end{array}$ & $\begin{array}{l}\text { Que alunos entendessem o sentido do grupo e conseguissem trabalhar em grupo; que conseguissem } \\
\text { identificar os vários tipos de texto; que tivessem acesso ao material, lessem, observassem e, ao final, } \\
\text { falassem como classificaram e que conseguissem pensar. }\end{array}$ \\
\hline $\begin{array}{l}\text { Efeitos obtidos com a utiliza- } \\
\text { ção das estratégias }\end{array}$ & $\begin{array}{l}\text { O efeito foi bom, pois eles tiveram a oportunidade de sentar junto e se entender, porém, identificou nomi- } \\
\text { nalmente alunos que não deram mostras de querer aprender. Nestes, notou indiferença, dispersão e } \\
\text { apatia em relação ao resto da sala. Alunos puderam pensar, mas para alguns foi mais difícil, pois têm } \\
\text { dificuldade em ficar parado, prestar atenção. O lado positivo é que estes alunos tiveram oportunidade de } \\
\text { pensar melhor sobre o tema. Leram, viram, pensaram e analisaram, mas identificou que alguns observa- } \\
\text { ram com mais propriedade do que outros. Maioria da sala fez a atividade. }\end{array}$ \\
\hline $\begin{array}{l}\text { Medidas comportamentais } \\
\text { correspondentes aos efeitos }\end{array}$ & $\begin{array}{l}\text { Alunos brigaram, falaram e quiseram se expor. Toda hora teve que parar e retomar o assunto. Mencionou } \\
\text { ter notado que alguns alunos faziam atividades diferentes do solicitado. Alunos falaram para a classe e } \\
\text { nos grupos. Percebeu que alunos queriam fazer a atividade. Notou que alguns alunos começavam a fazer } \\
\text { e depois paravam. Identificou que alguns fizeram por conta do grupo. }\end{array}$ \\
\hline $\begin{array}{l}\text { Possíveis influências dos } \\
\text { efeitos para o ensino do tema }\end{array}$ & $\begin{array}{l}\text { Influenciou, mas fez o que já tinha pensado; influenciou nas estratégias e na metodologia, mas não no } \\
\text { objetivo. Fez perguntas diferentes para cada grupo, de acordo com as argumentações apresentadas. }\end{array}$ \\
\hline
\end{tabular}


$\mathrm{Na}$ Etapa 1, os episódios selecionados das aulas ministradas na UD1 e exibidos à P1 objetivaram salientar características de atuação reincidentes: a) ensinar a trabalhar em grupo como um repertório definido por montar equipes, expor as tarefas em termos da explicitação das respostas finais previstas e indagar os membros da equipe sobre tais respostas e não sobre o trabalho em equipe; b) solicitar oralmente desempenhos com novas informações prescindindo do fornecimento de relações entre as exigências atuais e os repertórios prévios exibidos pelos alunos, tampouco de modelos de execução das atividades solicitadas; c) apresentar simultaneamente diferentes atividades (expor e questionar oralmente sobre conteúdos, redigir na lousa), sendo que diante de tal situação, o predomínio de respostas dos alunos incompatíveis com as previstas ("desatenção", conversas paralelas, copiar sem interação verbal com P1) pode sugerir concorrência entre contingências de reforço. Antes do contato com os episódios das aulas da UD1, o relato de P1 (Tabela 1) sugere controle pelas propriedades topográficas das interações: P1 relata, na exposição inicial ao Roteiro 1, uma síntese de suas ações e informa, quando indagado sobre efeitos e respectivas medidas comportamentais, ações dos alunos. Ao fazê-lo, o relato prescinde da proposição de possíveis vínculos funcionais entre tais ações e as condições diante das quais a ocorrência das mesmas foi observada. Os dados da Tabela 3 evidenciam efeitos seletivos da exposição aos episó- dios da Tabela 2. Após o contato com os episódios, P1 descreveu características dos desempenhos dos alunos e do próprio P1 ausentes na exposição inicial ao Roteiro 1. Assim, a exposição aos episódios fortaleceu o controle pelas propriedades topográficas. Mesmo após o contato com os episódios, foram verificados, na Tabela 3, relatos que informam sobre as ações dos alunos, mas, replicando os dados da Tabela 1, desvinculados da descrição das condições de sala de aula possivelmente vinculadas, de modo funcional, com tais ações. Em suma, os dados da Etapa 1 demarcaram discrepâncias entre, por um lado, os repertórios manifestos na atuação de P1 em sala de aula e os respectivos relatos sobre eles e, de outro, os repertórios que definem a execução de avaliações funcionais descritivas.

Etapa 2/Fase 1. A exposição ao Roteiro de Entrevista 2 foi iniciada com a replicação de questionamento sobre os objetivos das aulas da UD1. Como indicado na Tabela 4, abaixo, cada objetivo mencionado foi designado com um número distinto, sendo que as respostas fornecidas para as três questões restantes foram vinculadas separadamente com cada objetivo mencionado. Deste modo, os relatos identificados com o número 1 na coluna direita da Tabela 4 para as questões 2,3 e 4 foram vinculados com o objetivo 1 mencionado em resposta à questão sobre os objetivos (questão 1).

TABELA 4

Síntese das Respostas de P1 ao Roteiro de Entrevista 2

\begin{tabular}{|c|c|}
\hline Questões / Roteiro 2 & Síntese das respostas emitidas por P1 \\
\hline Objetivos & $\begin{array}{l}1 \text { - entendessem o sentido do grupo e conseguissem trabalhar em grupo; } \\
2 \text { - conseguissem identificar os vários tipos de texto em diferentes lugares; } \\
3 \text { - tivessem acesso ao material, lessem, observassem e, ao final, falassem como classificaram e que conse- } \\
\quad \text { guissem pensar. }\end{array}$ \\
\hline $\begin{array}{l}\text { 2. Estratégias de ensino } \\
\text { utilizadas }\end{array}$ & $\begin{array}{l}1 \text { - dividir a sala em grupo de três alunos; } \\
2 \text { - fazer exploração teórica do tema utilizando lousa; } \\
3 \text { - fornecer textos para alunos observarem; pedir produção de texto sobre o assunto discutido. }\end{array}$ \\
\hline $\begin{array}{l}\text { 3edidas prévias ao } \\
\text { contato com as es- } \\
\text { tratégias de ensino } \\
\text { em relação aos } \\
\text { objetivos }\end{array}$ & $\begin{array}{l}1 \text { - não sabiam trabalhar em grupo; nada faziam e deixavam as pessoas fazerem por eles; } \\
2 \text { - nada faziam sobre isto; faziam outras coisas diferentes em relação à aula; } \\
3 \text { - não tinham acesso a este material; não sabiam classificar; talvez soubessem sobre a existência de dife- } \\
\text { rentes tipos de escrita, mas não sabiam observar um tipo de texto. }\end{array}$ \\
\hline $\begin{array}{l}\text { 4. Medidas posteriores } \\
\text { ao contato com as } \\
\text { estratégias de ensino } \\
\text { em relação aos } \\
\text { objetivos }\end{array}$ & $\begin{array}{l}1 \text { - não atingiram os objetivos, apesar das diferenças de desempenho entre eles; a maneira como sentaram } \\
\text { em grupo e as oportunidades de conversar entre si foram ganhos, mas os objetivos não foram atingidos; } \\
2 \text { - não tiveram muito desenvolvimento apenas com esta parte oral; houve envolvimento, eles se expuseram } \\
\text { na frente da sala, mas o que se sobressaiu foi o grupo; as identificações orais não foram feitas de modo } \\
\text { convincente por cada membro do grupo; } \\
3 \text { - alguma coisa da atividade ficou proporcionada pelo ambiente; eles não conseguiram classificar; houve } \\
\text { observação, leitura, mas a classificação acredito que não. }\end{array}$ \\
\hline
\end{tabular}


P1 replicou o relato sobre os objetivos já emitido diante do roteiro anterior na Etapa $1 /$ Fase 3. Além disso, há referência sucinta às estratégias de ensino, indicando restrições de controle das ações emitidas e da exposição aos registros em vídeo sobre o repertório descritivo das ações (práticas de ensino e de avaliação) vinculadas com cada objetivo. Por exemplo, ao mencionar "fazer a exploração teórica", o relato prescinde da descrição das ações que definem o fazer tal exploração. Tal restrição de controle sugere que, para P1, objetivos como "(1) entender o sentido...", "(3)... falassem como classificaram e que conseguissem pensar" seriam obtidos mediante a mera divisão da "sala em grupos" ou pela solicitação de "texto sobre o assunto discutido". Os dados exibidos na Tabela 4 reafirmam a insuficiência da exposição ao vídeo das aulas para atuar como condição instrucional sobre o repertório descritivo das ações emitidas por P1 ao ensinar e ao avaliar a aprendizagem de determinados conteúdos curriculares. Quanto às demais questões do Roteiro 2, o relato sobre as medidas prévias (questão 3) caracterizou-se pela reincidência de expressões sobre a ausência de repertórios e não pela descrição de propriedades daqueles efetivamente emitidos. Esta característica foi igualmente registrada no relato sobre as medidas posteriores. Descrições da ausência de repertórios apresentam-se como uma característica antagônica à proposição de possíveis vínculos funcionais entre propriedades do ambiente e das ações dos alunos e de P1.

Etapa 2/Fase 2. Na sequência, o vídeo com as aulas da UD1 foi reapresentado na íntegra, com indicação, a exemplo da etapa anterior, do início e do final dos episódios selecionados. Finalizada a exibição do vídeo, o modelo de avaliação funcional descritiva, expresso na Tabela 5 e elaborado pelos pesquisadores sobre os episódios da UD1, foi exposto à P1 oralmente e por escrito.

\section{TABELA 5}

Modelo de Avaliação Funcional Descritiva Exposto à P1 Sobre os Episódios da UD1

\begin{tabular}{|c|c|}
\hline Episódios & Características \\
\hline \multirow{4}{*}{$1,2,3$ e 4} & $\begin{array}{l}\text { Os trechos selecionados no vídeo das aulas da UD1 ilustram a ocorrência de três desempenhos dos alunos para as quais } \\
\text { gostaríamos de concentrar atenção: }\end{array}$ \\
\hline & $\begin{array}{l}\text { 1a. Desempenho) cópia (transcrição) não solicitada de informaç̃̃es. A ocorrência destas respostas foi registrada diante das } \\
\text { seguintes condições antecedentes: a) solicitação de discussões em grupos, com restriçães de acesso dos membros do } \\
\text { grupo aos textos (número insuficiente de cópias para todos os membros do grupo); b) exigências posteriores de manifesta- } \\
\text { ção destas mesmas informações; c) instruções de P1 que prescindiram da designação das tarefas específicas de cada } \\
\text { membro do grupo (o que se esperava que cada um fizesse, pressupondo conhecimento prévio sobre a existência de tais } \\
\text { repertórios), com descrição das topografias de respostas e de controle de estímulo desejadas; d) parte expressiva do suporte } \\
\text { para a realização das atividades solicitadas ao grupo concentrou-se em informações orais fornecidas previamente por P1, } \\
\text { sem a obtenção de medidas de compreensão de tais informações. As ocorrências de cópia diante destas condições antece- } \\
\text { dentes parecem não ter contribuído para a obtenção de resultados favoráveis, considerando os objetivos pretendidos. Ou } \\
\text { seja, as ocorrências de cópia após tais antecedentes foram seguidas pela avaliação negativa do professor quanto ao de- } \\
\text { sempenho dos alunos. }\end{array}$ \\
\hline & $\begin{array}{l}2^{a} \text {. Desempenho) relatos dos alunos discrepantes dos previstos. Diante da tarefa de expor oralmente para os demais alunos } \\
\text { os textos que foram analisados por cada grupo, foram registradas discrepâncias entre o relato dos alunos e as medidas } \\
\text { previstas ou esperadas pelo professor. Tais discrepâncias foram registradas diante das seguintes condições: a) P1 fez } \\
\text { exposição oral dos diferentes tipos de texto, mas cada grupo tinha acesso somente ao seu texto para análise e classificação, } \\
\text { restringindo as possibilidades de relacionar características textuais mencionadas por P1 com a redação correspondente de } \\
\text { outros textos; b) P1 mencionou as características que definiam cada um dos diferentes tipos de texto que seriam estudados, } \\
\text { mas prescindiu da obtenção de quaisquer medidas de compreensão dos alunos sobre tais características; c) Tais informa- } \\
\text { ções foram apresentadas oralmente, quando P1, de modo simultâneo, colocava na lousa informações para cópia dos alunos, } \\
\text { caracterizando uma situação de concorrência entre prestar atenção nas explicações orais de P1 ou copiar as informações } \\
\text { expostas na lousa. Deste modo, diante de tais condições antecedentes, os desempenhos dos alunos (relatos e redação } \\
\text { sobre os diferentes tipos de texto) foram estimados como insatisfatórios. }\end{array}$ \\
\hline & $\begin{array}{l}3^{a} \text {. Desempenho) Ações que P1 definiu como desinteresse, dispersão e concorrente com o prestar atenção. Tais respostas } \\
\text { foram observadas diante da apresentação de materiais adicionais (livros e textos ilustrativos) simultaneamente às explica- } \\
\text { ções do professor. Estas respostas dos alunos, registradas sob condição de estimulações variadas e simultâneas, foram } \\
\text { avaliadas (produziram efeitos) como inadequadas. }\end{array}$ \\
\hline
\end{tabular}

As análises descritas na Tabela 5 concentraram ênfase em explicitar e descrever as condições diante das quais três classes de respostas emitidas pelos alunos e exibidas no vídeo e nos episódios selecionados foram registradas. Tais análises objetivaram colocar P1 em contato com um modelo de interpretação das ações 
dos alunos e do professor distinto daquele demonstrado por P1 até aquele momento do procedimento. Assim, a avaliação do primeiro desempenho concentrou ênfase em destacar as circunstâncias diante das quais a emissão do copiar ocorreu, bem como as discrepâncias registradas entre os repertórios previstos e aqueles observados diante da emissão do copiar. A avaliação do segundo desempenho focalizou, com maior diversidade, algumas das condições que antecederam e que foram posteriores à observação de repertórios distintos dos previsto. Por seu turno, o terceiro desempenho consistiu nos repertórios que P1 estimou como antagônicos com o "prestar atenção". A avaliação proposta destacou características das ações de P1 antecedentes e subsequentes à ocorrência de tais repertórios.

Etapa 2/Fase 3. A Fase 3 foi iniciada com a exibição, na íntegra, do vídeo das aulas da UD2. Durante a exibição, o pesquisador sinalizou o início e o final do episódio selecionado da UD2, informando que o mesmo seria objeto de discussão ao final da exibição do vídeo. $\mathrm{O}$ episódio foi selecionado com base nos mesmos critérios que orientaram a seleção dos episódios das aulas da UD1. Em função das restrições na disponibilidade de tempo de P1, decidiu-se pela seleção e exibição de somente um episódio das aulas da UD2. A Tabela 6 informa sobre as principais características do episódio selecionado da UD2.

TABELA 6

Principais Características do Episódio Selecionado das Aulas Ministradas por P1 na Unidade Didática 2 (UD2), Cujo Tema foi "Texto Científico"

\begin{tabular}{l|l}
\hline Episódio & Características \\
\hline \multirow{1}{*}{1} & $\begin{array}{l}\text { P1 mencionou as características do texto científico e as escreveu na lousa. A turma foi dividida em grupos de três alunos. P1 } \\
\text { sorteou temas diferentes para a produção do texto científico. Distribuiu materiais (livros e dicionários) para os grupos con- } \\
\text { sultarem sobre os respectivos temas sorteados. Solicitou que cada aluno pesquisasse sobre o tema do grupo como tarefa de } \\
\text { casa. Pediu para alunos responderem a } 3 \text { questões sobre o tema do seu grupo (Explique o que é, onde podemos encontrar e } \\
\text { dê exemplos). Solicitou um único texto científico para o grupo e escolheu um escriba para ser o responsável por escrevê-lo. } \\
\text { Forneceu instruções orais sobre como escrever o texto científico. } \\
\text { Na aula subsequente, após ler os textos dos alunos, P1 os comentou, apontando insatisfação com o desempenho dos alu- } \\
\text { nos e dizendo que pareciam mais com textos de opinião do que com textos científicos. P1 disse aos alunos que os textos } \\
\text { eram cópias dos livros ou baseados no "achômetro". } \\
\text { Em seguida, P1 entregou os textos aos alunos e solicitou a leitura e a reescrita dos mesmos. }\end{array}$ \\
\hline
\end{tabular}

Imediatamente após a exibição do vídeo das aulas da UD2, com a sinalização do episódio selecionado,
P1, em resposta à solicitação, apresentou as análises descritas na Tabela 7.

TABELA 7

Síntese das Análises de P1 Sobre o Episódio das Aulas da UD2

\begin{tabular}{l|l}
\hline Episódio & Características \\
\hline 1 & $\begin{array}{l}1^{a} \text {.) as perguntas que foram elaboradas para as crianças responderem (explique o que é, onde podemos encontrar, dê } \\
\text { exemplos) deveriam orientar a produção do texto científico, de modo a facilitar a obtenção dos objetivos (analisar, classificar } \\
\text { e compreender o texto científico), embora reconheça confusões para a compreensão pelas crianças. As perguntas e as } \\
\text { conversas entre o professor e os alunos contribuíram para um melhor aproveitamento; }\end{array}$ \\
$\begin{array}{l}2^{\text {a }} \text {.) as condições oferecidas em sala de aula (exposição oral dos alunos, correção das atividades do grupo, respostas dos } \\
\text { alunos às indagações orais de P1) aparentemente sugeriam uma compreensão satisfatória dos alunos, a julgar pelo desem- } \\
\text { penho oral dos mesmos. Contudo, a produção escrita (texto científico) dos alunos foi insatisfatória e indicou a discrepância } \\
\text { entre os desempenhos escrito e oral; } \\
3^{a} \text {.) respostas de atentar dos alunos foram mais acentuadas diante das atividades de cópia. }\end{array}$ \\
\hline
\end{tabular}

A síntese do relato verbal de P1 expressa na Tabela 7 evidenciou características que distanciam tal relato das análises iniciais registradas nas exposições ao Roteiro 1, bem como as aproximam do modelo expresso na Tabela 5. Dentre tais características, caberia destacar as hipóteses sobre as condições em que as interações professor-aluno ocorreram e que poderiam ter contribuído para um melhor aproveitamento dos alunos e a identificação da possível independência entre os desempenhos escrito e oral. Em ambas, o relato de P1 mostrou-se distante da proposição de possíveis relações de causa à fatores intrínsecos aos 
alunos. Diferentemente, foram propostos possíveis vínculos entre as ações observadas dos alunos e as condições de ensino dispostas pelo professor, de modo semelhante ao expresso no modelo descrito na Tabela 5. Esta semelhança pode se constituir em medida da aprendizagem objetivada nesta etapa do procedimento ou, de modo antagônico, em medida do efeito da exposição recente (Etapa 2/Fase 2) ao modelo de avalia- ção funcional elaborado pelos pesquisadores (Tabela 5).

Finalizando a Etapa 2, os pesquisadores apresentaram um modelo de avaliação funcional descritiva para o mesmo trecho exibido para P1 das aulas da UD2. O modelo foi descrito na Tabela 8 .

TABELA 8

Modelo de Avaliação Funcional Descritiva Exposto à P1 Sobre o Episódio da UD2

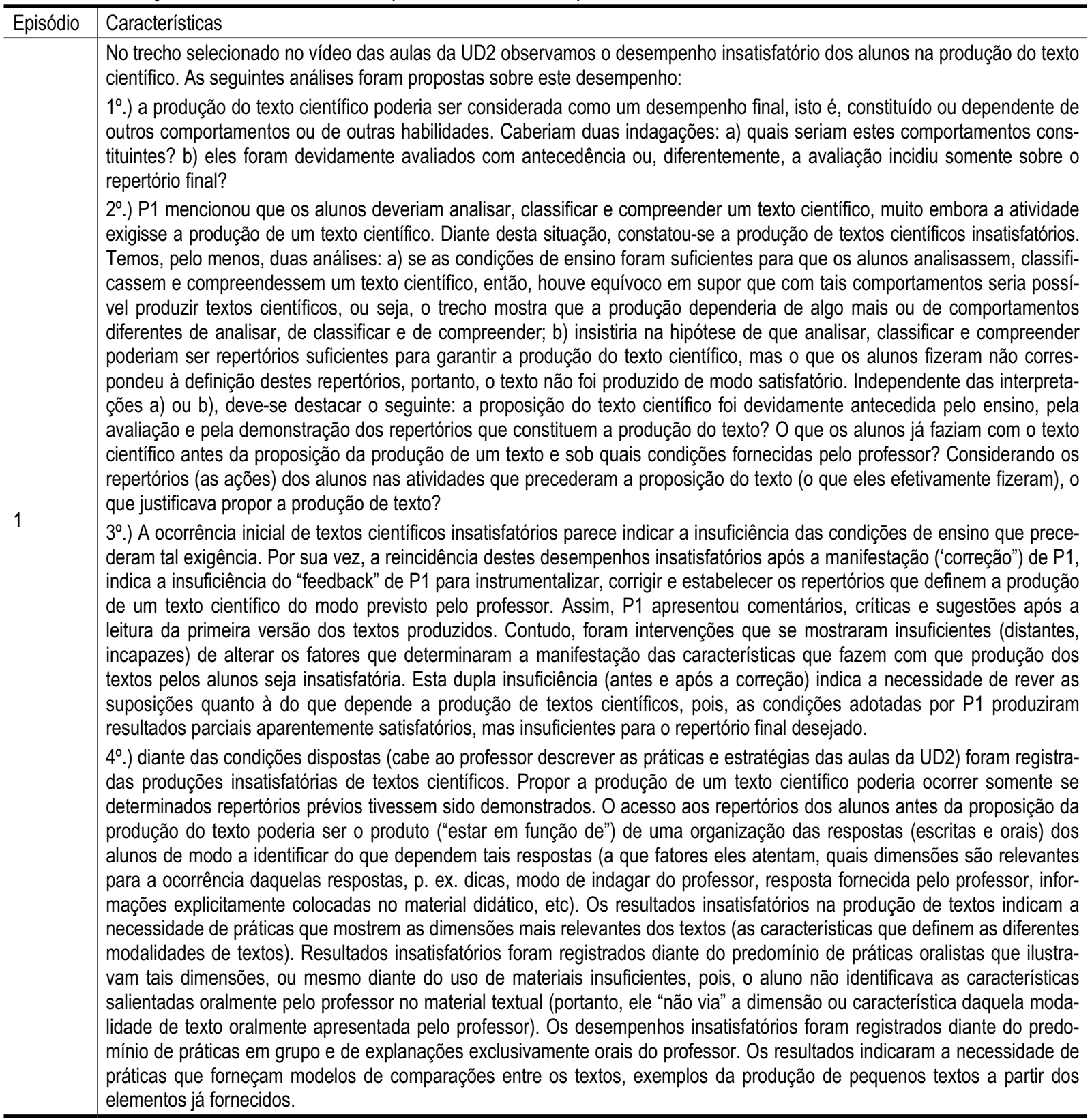


Em termos comparativos, o relato de P1 (Tabela 7) expressa avaliação do desempenho dos alunos ("confusões, produção insatisfatória, discrepância") e proposta de vinculação entre tais avaliações com o contexto da sala de aula. Entretanto, o relato de P1 mostra-se com restritas funções informativas sobre as condições (práticas) dispostas por P1 e diante das quais os repertórios dos alunos foram registrados. Informações sobre tais condições foram priorizadas no modelo de avaliação funcional descritiva exposto pelos pesquisadores (Tabela 8).

Etapa 3/Fase 1. P1 escolheu o tema "Texto publicitário" para a UD3. Na Fase 1 ocorreram os registros em vídeos das aulas ministradas sobre este tema.

Etapa 3/Fase 2. Após o término das gravações das aulas da UD3, foram selecionados episódios utilizados nas interações posteriores com P1. A Tabela 9 descreve as principais características dos episódios selecionados das aulas da UD3.

TABELA 9

Principais Características de Cada Episódio Selecionado das Aulas Ministradas por P1 na Unidade Didática 3 (UD3), Cujo Tema foi "Texto Publicitário"

\begin{tabular}{l|l}
\hline Episódio & Características \\
\hline 1 & $\begin{array}{l}\text { P1 utilizou estratégias predominantemente orais de exposição do conteúdo. Durante a exposição, emitiu perguntas que } \\
\text { exploravam dimensões já apresentadas previamente. As indagações de P1 foram direcionadas aos alunos que respon- } \\
\text { diam menos durante a realização de questões gerais. Diante da emissão de questões aos alunos, P1 permaneceu, a } \\
\text { exemplo das aulas já ministradas, ouvindo as respostas dos alunos, sem registro escrito das mesmas, desta feita, po- } \\
\text { rém, sem antecipar as respostas. }\end{array}$ \\
\hline $\begin{array}{l}\text { Após explicação oral sobre o texto publicitário, com exemplos de propaganda e folheto, P1 distribuiu revistas aos alunos } \\
\text { e solicitou que eles identificassem textos publicitários nela. A instrução foi a seguinte: "Vocês podem observar e vocês } \\
\text { vão escolher uma propaganda. Recortem a propaganda, analisem, leiam". Durante a realização da atividade de identifi- } \\
\text { cação do texto publicitário na revista, P1 informou: "Não adianta mostrar pra mim porque eu não vou falar se é uma } \\
\text { propaganda ou se não é uma propaganda. Tem coisa que é uma propaganda e tem coisa que não é. Tem coisa que é } \\
\text { um texto publicitário, que é uma propaganda, tem coisa que não é. Então eu quero que vocês se concentrem e achem } \\
\text { uma propaganda para cada pessoa". Os alunos folhearam as revistas e mostraram o que eles achavam ser a resposta } \\
\text { correta a P1. O professor disse que não falaria nada. Depois, os alunos apresentaram suas propagandas para a classe, } \\
\text { mas P1 solicitou apenas que eles apresentassem o texto de propaganda identificado, sem falar sobre as características } \\
\text { dos mesmos. P1 introduziu modelos prévios de textos publicitários com descrição oral de propriedades dos estímulos } \\
\text { (textos) que os definem. }\end{array}$ \\
\hline $\begin{array}{l}\text { Durante a exposição oral, professor explicou o significado das palavras utilizadas durante as instruções orais e escritas. } \\
\text { Durante a instrução escrita, P1 explicou detalhadamente o desempenho que esperava dos alunos. Quando os alunos } \\
\text { demonstraram dificuldades em responder às questões escritas, o professor as explicou para toda a classe. O professor } \\
\text { conversou com todos os alunos para esclarecer dúvidas e acompanhar o desempenho diante das tarefas solicitadas, } \\
\text { oferecendo assistência individual após instruções gerais. }\end{array}$ \\
\hline
\end{tabular}

Diante da exibição do vídeo das aulas da UD3, a exemplo do procedimento adotado nas etapas anteriores, os pesquisadores sinalizaram o início e o final dos episódios selecionados. Finalizada a apresentação do vídeo, as discussões sobre os episódios foram orientadas com base no Roteiro da Entrevista 3. A Tabela 10 expõe uma síntese das respostas fornecidas por P1. 
TABELA 10

Síntese das Respostas Fornecidas por P1 na Entrevista Realizada na Etapa 3/Fase 2

\begin{tabular}{l} 
Roteiro de Entrevista 3 \\
\hline Análise realizada pelo professor \\
com base nos aspectos mais \\
importantes observados por ele
\end{tabular}

Síntese das respostas emitidas por $\mathbf{P 1}$

"Eu tentei fazer o melhor que eu pude e tentei ser o mais claro e específico possível, por isso que deu um pouco mais de horário, mais de tempo, porque aquela questão que a gente já tinha conversado antes, eu tentei colocar, de observar se as crianças estavam entendendo, de passo-apasso, de esperar, de ter uma resposta deles pra ver se eles estavam entendendo mesmo" "são todos os momentos enquanto eu estava explicando, geralmente era uma resposta oral, então eu perguntava, então eu fiz mais isso do que em outras vezes, eu procurei me certificar que eles estavam entendendo passo-a-passo, isso foi a todo momento, toda atividade, sendo oral ou não, eu procurava perguntar pra eles, observar se eles estavam entendendo ou não". "Só que, assim, eu achei, nesse caso, que tinham duas qualidades que são diferentes que eu percebi. Uma que é assim: é interessante explicar como se não soubesse nada, só que tem momentos que eu percebo, parece que pra algumas crianças, quanto mais explica, complica mais". "Eu imagino que esse equilibrio tem que ter, às vezes, nem precisa ser tanto, eu aprendi isso, eu to dizendo aquilo que eu imagino que seja melhor pra fazer, às vezes, nem tanto explicar, mas aí vai do professor ficar ligado nisso ou não, equilibrar, às vezes, eu não preciso ser muito claro, porque, às vezes, eu posso acabar complicando mais e ir pra um outro lado que, às vezes, não é o caminho".

\begin{tabular}{l|l|l}
\hline Objetivos pretendidos & P1 declarou ter um objetivo final e vários objetivos intermediários a serem alcançados durante as
\end{tabular} aulas da UD3 "a gente pode colocar a produção de um texto publicitário, uma propaganda, esse era o produto final, era o objetivo. Agora várias partes tinham seu objetivo que era: a) identificar 0 texto de propaganda, o texto publicitário b) classificar o texto publicitário c) diferenciá-lo de um outro tipo de propaganda, de texto d) analisar o texto de propaganda, observar suas características. Esses eram os meu objetivos, cada dia teve um".

Desempenho dos alunos desejado $\quad$ "Eles tinham que mostrar, de alguma forma, que conseguiam diferenciar o texto publicitário de ao final da UD3 outro tipo de texto, isso que eu falei identificar" "A análise foi do começo ao final, eu acho que analisar foi em todas as aulas, a classificação foi num momento específico" "A classificação foi em dois momentos, no momento que eu apresentei a propaganda pra eles, que eles tinham que classificar realmente e de observar as diferenças entre um e outro".

\begin{tabular}{l|l}
\hline $\begin{array}{l}\text { Repertório de entrada dos alunos } \\
\text { em relação ao desempenho dese- } \\
\text { jado na UD3 }\end{array}$ & $\begin{array}{l}\text { Para P1, seus alunos "pelo contato com o texto publicitário já tinham uma noção" "então eles } \\
\text { podem ter mais facilidade de produzir também", embora não conhecessem todos os detalhes } \\
\text { envolvidos na preparação de uma propaganda. }\end{array}$ \\
\hline Estratégias de ensino utilizadas & $\begin{array}{l}\text { a) Explicação oral e dialogada sobre o texto publicitário; b) Produção diária dos alunos; c) Produ- } \\
\text { ção final dos alunos; d) Identificação do texto publicitário em comparação com outro texto; e) } \\
\text { Realização de trabalhos em grupo e f) Apresentação dos alunos. }\end{array}$ \\
\hline Estratégias de avaliação utilizadas & $\begin{array}{l}\text { "Eu tentei fazer aquilo lá, sempre observando na própria aula mesmo se eles estavam conseguindo } \\
\text { compreender, sempre perguntando pra eles se estava claro e fazendo perguntas e esperando } \\
\text { algum tipo de resposta, se a resposta não era basicamente aquilo, então eu voltava, tanto no oral } \\
\text { como no escrito também". }\end{array}$ \\
\hline Se os objetivos foram alcançados & $\begin{array}{l}\text { P1 disse que alcançou os objetivos com os alunos que frequentaram todas as aulas programadas. } \\
\text { "Eles me deram as respostas daquilo que eu considerava como objetivo alcançado. Quando eu } \\
\text { perguntava pra um, quando eu perguntava pra outro, ou mesmo quando eu não perguntava, mas } \\
\text { ia no lugar, mesmo para aquelas crianças que tinham dificuldades acabaram, interessante que } \\
\text { todo mundo, na sua particularidade, se esforçou e conseguiu fazer e me dar a resposta daquilo } \\
\text { que eu gostaria". }\end{array}$ \\
\hline $\begin{array}{l}\text { Medidas comportamentais que } \\
\text { sugerem alcance dos objetivos }\end{array}$ & $\begin{array}{l}\text { "Primeiro foram as respostas e também tem a produção ... a gente foi construindo as propagandas } \\
\text { e foi construindo a ideia, então isso que me diz que os objetivos foram alcançados". }\end{array}$ \\
\hline $\begin{array}{l}\text { Possíveis efeitos gerados no com- } \\
\text { portamento do professor }\end{array}$ & $\begin{array}{l}\text { "A todo o momento a avaliação ia de acordo com a obtenção ou não dos objetivos, então eu mu- } \\
\text { dava sempre, né. Foi aquilo lá que a gente tava conversando no começo, eu ia fazer uma coisa e } \\
\text { acabei fazendo outra por conta disso". }\end{array}$ \\
\hline
\end{tabular}

Após a aplicação do Roteiro de Entrevista 3, P1 efetuou uma análise comparativa entre as aulas ministradas nas unidades didáticas, encerrando a Etapa 3 do procedimento. P1 reconheceu, como características comuns, que nas unidades didáticas houve o predomínio de práticas orais, bem como de práticas nas quais os alunos tinham que expor publicamente o produto do trabalho para classe como um todo. Em termos das diferenças entre as aulas das três unidades didáticas, P1 relatou, em consonância com registros expostos nos episódios selecionados (Tabela 9), que nas aulas da UD3 pode-se observar a sua ênfase em fazer com 
que os alunos produzissem a resposta, sem antecipações do professor. Além disso, P1 relatou os esforços para explicar o máximo possível, fornecer exemplos (em especial, fornecer diferentes tipos de texto simultaneamente) e modelos para as indagações apresentadas, bem como a utilização de diferentes formas de avaliação do conteúdo. Ao final das análises comparativas, foi encerrado o procedimento de coleta de dados com P1.

\section{DISCUSSÃO}

Em termos mais genéricos, este estudo objetivou documentar contribuições da Análise do Comportamento para a pesquisa aplicada sobre o desenvolvimento profissional de docentes (Rodrigues, 2005; Zanotto, 2000). Especificamente, objetivou-se ensinar repertórios comportamentais que definem a execução de avaliação funcional descritiva para professores que ministram conteúdos curriculares de Língua Portuguesa nas séries iniciais do Ensino Fundamental.

Na Etapa 1, P1 evidenciou características de desempenho distintas daquelas que definem a execução de avaliações funcionais descritivas (Matos, 1999; Neno, 2003; Sturmey, 1996). P1 descreveu desempenhos dos alunos com ênfase nas propriedades topográficas das respostas, sendo que tais descrições desvincularam propriedades dos desempenhos das condições diante das quais a emissão dos mesmos foi registrada. Pode-se constatar consistência nas características dos repertórios que foram emitidos nas duas unidades didáticas iniciais (UD1 e UD2). Houve predomínio de práticas oralistas, com reduzidos exemplos e demonstrações dos repertórios comportamentais que definiam os objetivos selecionados dos temas abordados. Predominaram práticas que priorizavam a produção da resposta final esperada, prescindindo da avaliação e do estabelecimento dos repertórios intermediários. $\mathrm{Na}$ realidade, em reiteradas ocasiões, respostas parciais distintas das previstas foram corrigidas com o fornecimento da resposta desejada. P1 mencionou possíveis influências dos efeitos observados nas práticas de ensino, mas reconheceu que executou um planejamento já definido previamente. $\mathrm{O}$ contato com o vídeo parece ter favorecido o refinamento descritivo de características topográficas dos desempenhos do professor e dos alunos. Na entrevista, após o contato com o vídeo das aulas da UD1, P1 relatou efeitos e medidas comportamentais ausentes nas respostas fornecidas por ocasião da entrevista anterior, realizada na ausência do vídeo. Contudo, o contato com o vídeo mos- trou-se insuficiente para sinalizar ou informar sobre relações de contingências ou relações de controle de estímulo (McIlvane \& Dube, 2003; De Rose, 2004). Deste modo, as características dos desempenhos relatados por P1 (cansaço, agitação, desatenção) não foram vinculadas com as condições de ensino e de avaliação disponibilizadas e, tampouco, as fontes de controle possivelmente relacionadas com a emissão de respostas previstas foram mencionadas. O delineamento adotado na Etapa 1 permitiu constatar que práticas e estratégias de ensino que prescindiram da execução de avaliações funcionais descritivas, ou seja, de interpretações de possíveis funções de determinados repertórios, foram acompanhadas por relatos que vincularam características de desempenho dos alunos com fatores intrínsecos aos mesmos.

$\mathrm{Na}$ Etapa 2, os dados da entrevista efetuada na Fase 1, sobre interações registradas nas aulas da UD1, foram redundantes em relação àqueles obtidos na etapa anterior para efeito de elaboração do primeiro modelo de avaliação funcional descritiva pelos pesquisadores. P1, na sua análise das aulas da UD2, relatou as discrepâncias entre as produções orais e escritas dos alunos. Desta feita, ou seja, após o contato com o modelo de avaliação funcional descritiva elaborado pelos pesquisadores (Tabela 5), as discrepâncias não foram vinculadas com características intrínsecas dos alunos. Diferentemente, P1 mencionou características do desempenho dos alunos na produção de texto nas condições de sala de aula. Contudo, o relato mostrou-se deficiente em termos da visibilidade fornecida para propriedades topográficas e funcionais destas condições (Tabelas 7 e 8).

$\mathrm{Na}$ Etapa 3, as mudanças constatadas no repertório de P1 nas aulas ministradas (Tabela 9) e nas análises de algumas das interações registradas nas mesmas (Tabela 10) poderiam: a) expressar o produto de avaliações funcionais realizadas por P1 sobre as discrepâncias entre as medidas oral e escrita registradas na produção do texto científico, demarcando, portanto, medidas da aprendizagem objetiva neste estudo; ou b) expressar o controle das análises anteriores expostas pelos pesquisadores sobre o desempenho de P1 em sala de aula e em respostas ao Roteiro 3. Os desempenhos de P1 nas aulas ministradas na Etapa 3 evidenciaram mudanças consistentes com as análises efetuadas na etapa anterior. Por sua vez, os desempenhos nas análises verbais mostraram-se inconclusivos em termos da eficácia dos procedimentos adotados para desenvolver repertórios que expressem a identificação de possíveis relações de controle entre dimensões 
envolvidas no ensino e na aprendizagem de conteúdos curriculares. As semelhanças entre os temas selecionados para as três unidades didáticas e, principalmente, características do relato de P1 na entrevista da Etapa 3 (Tabela 10), na qual P3 praticamente replicou dimensões das medidas comportamentais previamente salientadas no modelo de avaliação funcional descritiva elaborado pelos pesquisadores (Tabela 5), sugere um alcance restrito dos procedimentos adotados na aprendizagem de novos repertórios por P1. Os resultados expostos nos episódios selecionados sugerem possíveis contribuições dos procedimentos adotados para a manifestação de repertórios de ensino e de avaliação por P1, em sala de aula, consistentes com os respectivos modelos elaborados pelos pesquisadores. Contudo, a extensão desta aprendizagem para repertórios que definem a execução de avaliações funcionais descritivas apresenta-se de modo inconclusivo. Praticamente P1 respondeu, na entrevista da Etapa 3, às mesmas dimensões ressaltadas nas análises anteriores expostas pelos pesquisadores. O procedimento adotado privou P1 de condições para manifestar a aprendizagem objetivada, evidenciando propriedades de generalização de estímulos.

Considerando os objetivos que justificaram a realização deste estudo, estima-se que a execução dos procedimentos previstos nas três etapas viabilizou a ampliação de estratégias de programas de pesquisa que, em consonância com tendências recentes da literatura (Fox \& Davis, 2005; Scott \& cols., 2005; Ulian, 2007; van Acker, 2005), priorizam a implantação dos recursos metodológicos da avaliação funcional descritiva em contextos aplicados.

Outrossim, os principais resultados acima salientados convergem em indicar que propriedades dos repertórios de P1 nas aulas ministradas na UD3 possivelmente mostram-se vinculadas funcionalmente com condições dispostas nos procedimentos adotados nas duas etapas iniciais.

As dificuldades de $\mathrm{P} 1$ para elaborar uma avaliação funcional descritiva das interações dispostas nas aulas das três unidades didáticas, replicam, ainda que parcialmente, evidências da literatura (Scott \& cols., 2005; van Acker, 2005). Interpretações adicionais destas dificuldades que fundamentem propostas de continuidade das pesquisas demarcam contribuições da Análise do Comportamento para programas de investigação sobre formação continuada de professores e desenvolvimento profissional de docentes. Assim, no âmbito do delineamento adotado neste estudo, tais dificuldades poderiam sustentar relações de funciona- lidade com características do procedimento adotado. De modo mais específico, as apresentações dos modelos de avaliação funcional a P1 foram inseridas em situações nas quais o professor tinha acesso a todo o vídeo das aulas ministradas das quais os respectivos episódios foram retirados. Deste modo, o contato de P1 com as cenas dos episódios e com as análises funcionais descritivas propostas pelos pesquisadores ocorreram sob condições de excessiva estimulação visual, facilitando a ocorrência de relações de controle concorrentes com as previstas. Este mesmo excesso foi verificado quando P1 deveria elaborar ou propor um modelo de avaliação funcional de interações das aulas da UD2 e da UD3. Em síntese, o delineamento proposto garantiu o contato de P1 com o registro das interações em sala de aula em todas as etapas. Contudo, diante deste contato foram registradas medidas redundantes (Etapa 2/Fase 1) entre as etapas e fases, dificuldades na programação das sessões de coleta em razão do tempo necessário para a exibição dos vídeos e, principalmente, restrições no estabelecimento de relações de controle entre propriedades das interações selecionadas e o relato verbal de P1. Estudos adicionais deverão concentrar ênfase em investigar recursos metodológicos que garantam funções instrucionais do contato com os episódios, eliminando fontes de controle adventício por ocasião deste contato, viabilizando, portanto, a execução de avaliações funcionais descritivas de interações relevantes para o ensino e a avaliação da aprendizagem de conteúdos curriculares em sala de aula.

\section{REFERÊNCIAS}

Alves, W. (2007). A formação de professores e as teorias do saber docente: Contexto, dúvidas e desafios. Educação e Pesquisa, 33(2), 263-280.

Andery, M. A., Micheletto, N., \& Sério, M. T. (2001). Análise funcional na análise do comportamento. Em H. J. Guilhardi, M. B. Madi, P. P. Queiroz \& M. C. Scoz (Orgs.), Sobre comportamento e cognição: Vol. 8 - Expondo a variabilidade (pp. 148-157). Santo André: ESETec.

Bijou, S., Peterson, R., \& Ault, M. (1968). A method to integrate descriptive and experimental field studies at the level of data and empirical concepts. Journal of Applied Behavior Analysis, 1(2), 175-191.

Borrero, C., \& Borrero, J. (2008). Descriptive and experimental analysis of potential precursors to problem behavior. Journal of Applied Behavior Analysis, 41(1), 83-96.

Brasil (1997). Parâmetros Curriculares Nacionais: Primeiro e segundo ciclos do ensino fundamental/lingua portuguesa. Brasília: Secretaria de Educação Fundamental/SEF, Ministério da Educação. 
Carr, E. (1994). Emerging themes in the functional analysis of problem behaviors. Journal of Applied Behavior Analysis, 27, 393-399.

Carr, E. (1977) The motivation of self-injurious behavior: A review of some hypotheses. Psychological Bulletin, 84, 800816.

Daly, E., III, Witt, J., Martens, B., \& Dool, E. (1997). A model for conducting a functional analysis of academic performance problems. The School Psychology Review, 26(4), 554-574.

De Rose, J. C. C. (2004). Além da resposta correta: Controle de estímulo e o raciocínio do aluno. Em M. M. Hübner e M. Marinotti (Orgs.) Análise do comportamento para a educação: Contribuições recentes (pp. 103-113) Santo André: ESETec.

Evangelista, O., \& Shiroma, E. (2007). Professor: Protagonista e obstáculo da reforma. Educação e Pesquisa, 33(3), 531-541.

Fox, J., \& Davis, C. (2005). Functional behavior assessment in schools: Current research findings and future directions. Journal of Behavioral Education, 14(1), 1-4.

Hagopian, L., Fisher, W., Thompson, R., Owen-DeSchryver, J., Iwata, B., \& Wacker, D. (1997). Toward the development of structured criteria for interpretation of functional analysis data. Journal of Applied Behavior Analysis, 30, 313-326.

Horner, R. (1994). Functional assessment: Contributions and future directions. Journal of Applied Behavior Analysis, 27, 401-404.

Iwata, B., Wallace, M., Kahng, S., Lindberg, J., Roscoe, E., Conners, J., Hanley, G., Thompson, R., \& Worsdell, A. (2000). Skill acquisition in the implementation of functional analysis methodology. Journal of Applied Behavior Analysis, 33, 181194.

Lerman, D. C., \& Iwata, B. (1993). Descriptive and experimental analysis of variables maintaining self-injurious behavior. Journal of Applied Behavior Analysis, 26, 293-319.

Mace, F. (1994). The significance and the future of functional analysis methodologies. Journal of Applied Behavior Analysis, 27, 385-392.

Mace, F., \& Lalli, J. S. (1991). Linking descriptive and experimental analysis in the treatment of bizarre speech. Journal of Applied Behavior Analysis, 24, 553-562.

Matos, M. A. (1999). Análise funcional do comportamento. Estudos de Psicologia, 16(3), 8-18.

McIlvane, W., \& Dube, W. (2003). Stimulus control topography coherence theory: Foundations and extensions. The Behavior Analyst, 26(2), 195-213.

Meyer, K. (1999). Functional analysis and treatment of problem behavior exhibited by elementary school children. Journal of Applied Behavior Analysis, 32, 229-232.

Moore, J., Edwards, R., Sterling-Turner, H., Riley, J., DuBard, M., \& McGeorge, A. (2002). Teacher acquisition of functional analysis methodology. Journal of Applied Behavior Analysis, $35,73-77$.

Moore, J., \& Fisher, W. (2007). The effects of videotape modeling on staff acquisition of functional analysis methodology. Journal of Applied Behavior Analysis, 40, 197-202.

Neef, N. A., \& Iwata, B. (1994). Current research on functional analysis methodologies: An introduction. Journal of Applied Behavior Analysis, 27, 211-214.
Neno, S. (2003). Análise funcional: Definição e aplicação na terapia analítica-comportamental. Revista Brasileira de Terapia Comportamental e Cognitiva, 5(2), 151-165.

Noell, G., Witt, J., LaFleur, L., Mortenson, B., Ranier, D., \& LeVelle, J. (2000). Increasing intervention implementation in general education following consultation: A comparison of two follow-up strategies. Journal of Applied Behavior Analysis, 33, 271-284.

Nunes, D. (2008). Teoria, pesquisa e prática em educação: A formação do professor-pesquisador. Educação e Pesquisa, 34 (1), 97-107.

Repp, A. (1994). Comments on functional analysis procedures for school-based behavior problems. Journal of Applied Behavior Analysis, 27, 409-411.

Rodrigues, M. E. (2005). A contribuição do behaviorismo radical para a formação de professores: Uma análise a partir das dissertações e teses do período de 1972 a 2002. Tese de doutorado não-publicada, Pontifícia Universidade Católica de São Paulo.

Scarvodelli, E. (2006, 10 de agosto). O português desanda. Língua Portuguesa, Edição 29. Retirado em 10 de agosto de 2006, de http://www.revistalinguaportuguesa.com.br/textos.asp?codigo= 1116

Scott, T., Liaupsin, C., Nelson, M., \& McIntyre, J. (2005). Teambased functional behavior assessment as a proactive public school process: A descriptive analysis of current barriers. Journal of Behavioral Education, 14(1), 57-71.

Sidman, M. (1960). Tactics of scientific research: Evaluating experimental data in psychology. New York: Basic Books.

Sprague, J., \& Horner, R. (1992). Covariation within functional response classes: Implications for treatment of severe problem behavior. Journal of Applied Behavior Analysis, 25, 735-745.

Sturmey, P. (1996). Functional analysis in clinical psychology. Chichester: John Wiley.

Ulian, A. L. (2007). Uma sistematização da prática do terapeuta analítico-comportamental: Subsídios para a formação. Tese de doutorado não-publicada, Universidade de São Paulo.

Van Acker, R., Boreson, L., Gable, R., \& Potterton, T. (2005). Are we on the right course? Lessons learned about current FBA/BIP practices in schools. Journal of Behavioral Education, 14(1), 35-56.

Wallace, M., Doney, J., Mintz-Resudek, C., \& Tarbox, R. (2004). Training educators to implement functional analysis. Journal of Applied Behavior Analysis, 37, 89-92.

Zanotto, M. L. (2004). Subsídios da análise do comportamento para a formação de professores. Em M. M. Hübner e M. Marinotti (Orgs.), Análise do comportamento para a educação: Contribuições recentes (pp. 33-47). Santo André: ESETec.

Zanotto, M. L. (2000). Formação de professores: A contribuição da análise do comportamento. São Paulo: EDUC/FAPESP. 
Notas:

1 A literatura têm documentado, com relativo consenso, que a expressão análise funcional prioriza a descrição de modos de proceder na produção do conhecimento sem vincular compromissos epistemológicos e conceituais (Sturmey, 1996). Tal característica justificaria, no âmbito do Behaviorismo Radical e da Análise do Comportamento, substituir tal expressão por análise de contingências (Andery, Micheletto \& Sério, 2001; Neno, 2003; Ulian, 2007). Mesmo reconhecendo a relevância deste debate, estima-se que o mesmo não pertence ao escopo da investigação ora relatada. Em observância à tradição literária que fundamenta tal investigação, foi mantida a expressão análise funcional.

2 Pesquisa parcialmente financiada (CNPq Edital 61/2005 e Fundação de Amparo à Pesquisa do Estado de São Paulo FAPESP/Modalidade Auxílio à Pesquisa).

\section{Sobre os autores:}

Jair Lopes Junior: Professor Assistente Doutor da Universidade Estadual Paulista - Campus Bauru.

Ana Paula Araújo Fonseca: Mestre pela Universidade Estadual Paulista - Campus Bauru. Bolsista Mestrado FAPESP/MS.

Mariana Francisco Giuzio: Graduanda pela Universidade Estadual Paulista - Campus Bauru. Bolsista Iniciação Científica FAPESP/IC.

Endereço para correspondência: Prof. Jair Lopes Junior - UNESP/FC/Departamento de Psicologia - Av. Eng. Luiz Edmundo Carrijo Coube, 14-01 - 17033-360 Bauru/SP - Endereço eletrônico: jlopesjr@fc.unesp.br. 